\title{
HPV infection in HIV-positive subjects and molecular epidemiology
} K Protopas*1, S Tsiodras², K Chranioti², A Papadopoulos², P Panagopoulos',

\author{
J Georgoulakis², A Antoniadou², V Sakka², L Galani², D Kavatha², \\ G Poulakou², A Spathis², I Katsarolis², I Karaiskos², J Panagiotidis², \\ P Karakitsos $^{2}$ and HG Giamarellou ${ }^{2}$
}

\author{
Address: ${ }^{14}$ th Department of Internal Medicine, University General Hospital Attikon, Athens, Greece and ${ }^{2}$ Department of Cytology, University \\ General Hospital Attikon, Athens, Greece \\ * Corresponding author
}

\author{
from Ninth International Congress on Drug Therapy in HIV Infection \\ Glasgow, UK. 9-13 November 2008 \\ Published: 10 November 2008 \\ Journal of the International AIDS Society 2008, I I (SuppI I):P294 doi:I0.I I86/I758-2652-I I-SI-P294
}

This abstract is available from: http://www.jiasociety.org/content/I I/SI/P294

(C) 2008 Protopas et al; licensee BioMed Central Ltd.

\section{Purpose of the study}

We aimed to examine HPV infection of the anus in a cohort of HIV-infected patients and correlate cytological findings with molecular findings and immunological parameters.

\section{Methods}

The population of an HIV clinic is prospectively followed with Thin prep anal smear testing. Clinical arrays were used to identify HPV infection. HPV detection was examined in relation to epidemiological information, cytological changes and immunological parameters. Univariate and multivariate analysis were used.

\section{Summary of results}

105 pts (92.3\% male) with a median duration of HIV infection of 3 years (IQR: 1-7.8 years) have been examined. Mean value of current CD4 was 431.7 , b 223/mm3, and of current HIV viral load was $364.5 \mathrm{c} / \mathrm{mL}$ (IQR: nondetected $-9880 \mathrm{c} / \mathrm{mL}, 19 / 42<50 \mathrm{c} / \mathrm{mL}$ ). Cytological changes were detected in $62 \%$ of the population and high grade AIN in $3.7 \%$ of the population. HPV was detected with clinical arrays in $92 \%$ of the population. HPV detection by arrays correlated with the presence of cytological changes $(p=0.01)$. HPV positivity was associated with age $(p=0.02)$, number of sexual partners (five or more over the last year; $p=0.05)$, and lower CD4 counts $(p=0.02)$. After adjustment for age and number of sexual partners, only decreasing CD4 counts remained an important predictor of HPV positivity $(\mathrm{b}=-0.01, \mathrm{p}=0.03)$.

\section{Conclusion}

HPV infection was prevalent in this patient cohort and was associated with the number of sexual partners, lower CD4 counts and the development of cytopathological changes. HPV infection may be better controlled in HIV pts at a better immunological state. Prospective follow-up of HIV pts with HPV is necessary for the prevention of peri-anal malignancies. 